\title{
Sistem Informasi Perpustakaan Menggunakan Barcode Berbasis Web
}

\author{
Yati Nurhayati \\ ${ }^{1}$ Fakultas Ilmu Komputer Universitas Kuningan \\ E-mail: yati.nurhayati@uniku.ac.id
}

\begin{abstract}
Abstrak
Perpustakaan sebagai salah satu media yang menyediakan berbagai sumber ilmu pengetahuan yang terpercaya dalam bentuk buku, jurnal dan penelitian ilmiah lainnya. Untuk meningkatkan minat dalam membaca khususnya di lingkungan mahasiswa dan dosen maka perpustakaan perlu didukung dengan sebuah sistem yang dapat mengelola data perpustakaan secara cepat dan akurat. Pada saat ini, khususnya di Perpustakaan Fakultas Ilmu Komputer Universitas Kuningan aplikasi perpustakaan yang ada masih memiliki beberapa kendala yaitu system tidak dapat menampilkan stok buku yang ada dan jumlah buku yang dipinjam sehingga menyulitkan pustakawan dan mahasiswa untuk mengecek stok, untuk input dan pencarian buku masih diinputkan dengan cara diketik sehingga tidak efisien, untuk pencarian buku di perpustakaan fakultas lainnya harus memilih fakultas terlebih dahulu baru diketikkan keyword yang dicari sehingga harus mengecek satu per satu di berbagai fakultas, belum adanya pembagian kategori antara buku, jurnal ataupun skripsi dan laporan yang dihasilkan belum optimal. Adapun hasil dari penelitian ini berupa sebuah sistem informasi dmana didalamnya pustakawan dapat melakukan pengelolaan data koleksi berupa buku, jurnal, hasil penelitian mahasiswa/dosen (laporan kerja praktek/proposal skripsi/tugas akhir/skripsi/tesis/disertasi), koleksi lainnya (seperti majalah, surat kabar, dan lain-lain), pengelolaan transaksi peminjaman dan pengembalian buku, pengelolaan anggota perpustakaan, buku tamu dan laporan-laporan (buku yang tersedia, yang dipinjam, dan lain-lain). Sistem yang dikembangkan dapat membaca kode buku dan kode anggota berupa barcode sehingga memudahkan pencarian data ketika transaksi peminjaman/pengembalian terjadi. Setiap satu buku memiliki satu barcode, dimana untuk judul buku (termasuk pengarang, penerbit dan tahun terbit) yang sama memiliki kode yang sama, yang berbeda hanya kode dibelakang untuk per satuan buku, sehingga dapat diketahui buku ke-berapa yang dipinjam/tersedia/hilang walaupun judulnya sama. Sistem ini dirancang menggunakan DFD dan dikembangkan menggunakan metode RAD. Hasil perancangan diterapkan ke dalam Bahasa pemrograman PHP dan MySQL. Sistem informasi ini dapat digunakan oleh semua pustakawan di seluruh Fakultas di Universitas Kuningan dan pustakawan Universitas Kuningan, dimana masing-masing admin/pengguna hanya dapat mengelola data di masing-masing unit kerja-nya.
\end{abstract}

Kata Kunci-Perpustakaan, DFD, Barcode, MySQL, Sistem Informasi

\begin{abstract}
The library as one of the media that provides a variety of reliable sources of knowledge in the form of books, journals and other scientific research. To increase interest in reading, especially in students and lecturers, the library needs to be supported by a system that can manage library data quickly and accurately. At this time, especially in the University of Kuningan Faculty of Computer Science Library the existing library application still has several obstacles, namely the system cannot display the existing book stock and the number of books borrowed making it difficult for librarians and students to check stock, for input and search books are still input by typing it so that it is inefficient, to search for books in other faculties'
\end{abstract}


JURNAL NUANSA INFORMATIKA

Volume 13 Nomor 1, Januari 2019
p-ISSN : 1858-3911, e-ISSN : 2614-5405

https://journal.uniku.ac.id/index.php/ilkom

libraries, they must choose the first keywords that are searched so that they must check one by one in various faculties, there is no division of categories between books, journals or theses and the resulting reports are not optimal. The results of this study are in the form of an information system in which librarians can manage collection data in the form of books, journals, student I lecturer research results (practical work reports / thesis proposals / final assignments / theses / dissertations), other collections (such as magazines, newspapers, etc.), management of borrowing and returning books, management of library members, guest books and reports (available books, borrowed, etc.). The system developed can read book codes and member codes in the form of barcodes to facilitate data search when borrowing / returning transactions occur. Each book has one barcode, where the same title (including the author, publisher and published year) has the same code, the code is only the back for each book, so that the book can be borrowed / available / lost. even though the title is the same. This system is designed using DFD and developed using the RAD method. The design results are applied to the PHP and MYSQL programming languages. This information system can be used by all librarians in all faculties in Kuningan University and Kuningan University librarians, where each admin / user can only manage data in each work unit..

Keywords - Library, DFD, Barcode, MySQL, Information System

\section{PENDAHULUAN}

bahwa dengan membaca dapat meningkatkan kualitas hidup manusia serta menjauhkan dari jurang kebodohan. Membiasakan diri membaca buku, koran maupun media lainnya, merupakan sebuah latihan dalam memusatkan pikiran dan merangsang saraf otak untuk bekerja.[1]

Disinilah peran pentingnya perpustakaan sebagai salah satu media yang menyediakan berbagai sumber ilmu pengetahuan yang terpercaya dalam bentuk buku, jurnal dan penelitian ilmiah lainnya. Untuk meningkatkan minat dalam membaca khususnya di lingkungan mahasiswa dan dosen maka perpustakaan perlu didukung dengan sebuah sistem yang dapat mengelola data perpustakaan secara cepat dan akurat.

Syihabuddin Qalyubi (2003:4) menyatakan bahwa, "Perpustakaan, secara konvensional, yaitu kumpulan buku atau bangunan fisik tempat buku dikumpulkan, disusun menurut sistem tertentu untuk kepentingan pemakai".[2]

Menurut UU no 43 tahun 2007 disebutkan bahwa pustakawan adalah seseorang yang memiliki kompetensi yang diperoleh melalui pendidikan dan atau pelatihan kepustakawanan serta mempunyai tugas dan tanggung jawab untuk melaksanakan pengelolaan dan pelayanan perpustakaan.[3]

Pada saat ini, khususnya di Perpustakaan Fakultas Ilmu Komputer Universitas Kuningan aplikasi perpustakaan yang ada masih memiliki beberapa kendala yaitu system tidak dapat menampilkan stok buku yang ada dan jumlah buku yang dipinjam sehingga menyulitkan pustakawan dan mahasiswa untuk mengecek stok, untuk input dan pencarian buku masih diinputkan dengan cara diketik sehingga tidak efisien, untuk pencarian buku di perpustakaan fakultas lainnya harus memilih fakultas terlebih dahulu baru diketikkan keyword yang dicari sehingga harus mengecek satu per satu di berbagai fakultas, belum adanya pembagian kategori antara buku, jurnal ataupun skripsi dan laporan yang dihasilkan belum optimal.

"Sistem informasi adalah suatu sistem di dalam suatu organisasi yang mempertemukan kebutuhan pengolahan transaksi harian, mendukung operasi, bersifat manajerial dan kegiatan strategi dari suatu organisasi dan menyediakan pihak luar tertentu dengan laporan-laporan yang diperlukan", [4]

Oleh karena itu, untuk mengatasi berbagai permasalahan yang telah 
JURNAL NUANSA INFORMATIKA

Volume 13 Nomor 1, Januari 2019

dikemukakan tersebut maka dibutuhkan sebuah "Sistem Informasi Perpustakaan Menggunakan Barcode Berbasis Web"

\section{METODE PENELITIAN}

Tahapan kerangka pemikiran dapat dilihat pada Gambar 1

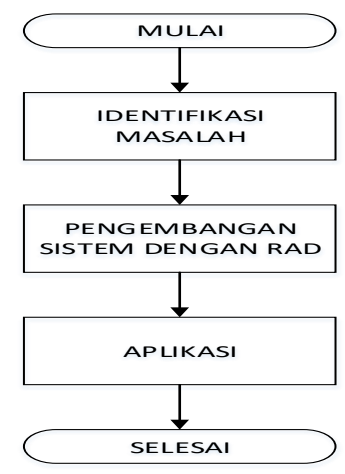

Gambar 1. Tahapan Kerangka Pemikiran

\subsection{Rapid Aplication Development(RAD)}

Rapid Application Development (RAD) adalah salah satu alternatif dari System Development Life Cycle digunakan untuk mengatasi keterlambatan dalam proses development.

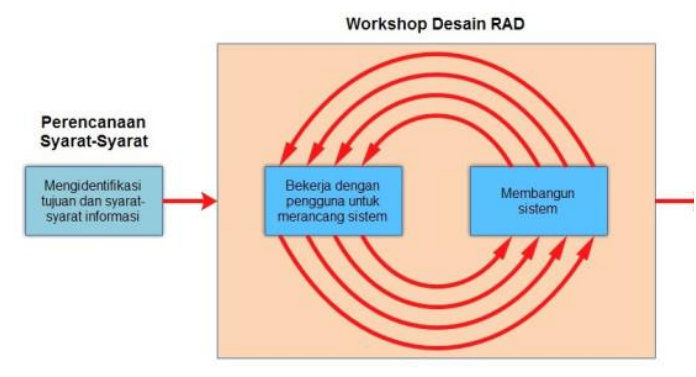

Gambar 2. Tahapan RAD (Kendall, 2010).

Adapun tahapan dari RAD adalah [5] :

a. Requirement Planning

Pada tahapan ini pengguna dan penganalisis bertemu untuk mengidentifikasikan tujuan aplikasi atau system serta untuk mengidentifikasikan syarat-syarat informasi yang ditimbulkan dari tujuan-tujuan tersebut. Orientasi dari tahap ini adalah menyelesaikan masalahmasalah perusahaan.
p-ISSN : 1858-3911, e-ISSN : 2614-5405

https://journal.uniku.ac.id/index.php/ilkom

b. RAD Design Workshop (Workshop Desain RAD)

Fase ini adalah fase untuk merancang dan memperbaiki yang bisa digambarkan sebagai workshop. Penganalisis dan dan pemrogram dapat bekerja membangun dan menunjukkan representasi visual desain dan pola kerja kepada pengguna.

c. Implementasi (Implementation)

Pada fase implementasi ini, penganalisis bekerja dengan para pengguna secara intens selama workshop dan merancang aspekaspek bisnis dan nonteknis perusahaan.

\subsubsection{Teknik Pengumpulan Data}

Teknik pengumpulan data yang digunakan dalam penelitian ini adalah :

a. Studi Pustaka

Pada teknik ini, data dikumpulkan dengan mempelajari berbagai dokumen, jurnal dan beberapa literature lainnya yang berkaitan dengan permasalahan yang diteliti mengenai data perpustakaan.

b.Wawancara

Selain studi pustaka, data juga diperoleh dengan melakukan sesi Tanya jawab dengan pihak-pihak yang berkaitan secara langsung dengan objek penelitian yaitu dengan pustakawan FKOM UNIKU sebagi sample.

c.Observasi

Agar didapatkan informasi mengenai aliran sistem dan data, maka perlu dilakukan pengamatan secara langsung pada saat kegiatan pengelolaan buku, peminjaman dan pengembalian buku

\subsection{2. $D F D$}

Sukamto dan Shalahuddin (2014:288), "Data Flow Diagram atau dalam bahasa Indonesia menjadi Diagram Alir Data (DAD) adalah refresentasi grafik yang menggambarkan aliran informasi dan transformasi informasi yang diaplikasikan sebagai data yang mengatur dari masukan (input) dan keluaran (output). DFD tidak sesuai untuk memodelkan sistem yang menggunakan pemograman berorientasi objek". [6] 
JURNAL NUANSA INFORMATIKA

Volume 13 Nomor 1, Januari 2019

Adapun notasi-notasi pada DFD sebagai berikut:

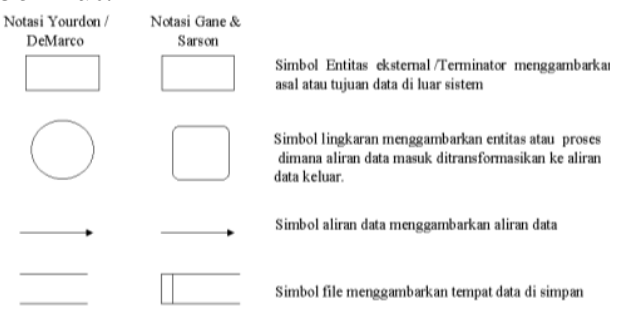

\section{HASIL DAN PEMBAHASAN}

Adapun hasil dan pembahasan dari penelitian ini adalah:

a. Requirement Plannning

Tahap pertama metodologi RAD adalah requirement planning dimana pada tahapan ini diperoleh informasi kebutuhan system secara fungsional dan non fungsional :

- Analisa Kebutuhan Sistem Fungsional

Adapun hasil Analisa kebutuhan sistem yang diperoleh sebagai berikut :

- Sistem hanya mengelola data anggota, data buku, kategori (buku, jurnal, skripsi, lainnya), data peminjaman, data pengembalian, denda. Sedangkan laporan yang dihasilkan berupa Laporan (Peminjaman, Laporan Peminjaman yang telah jatuh tempo, Pengembalian, Buku yang tersedia, buku yang hilang, buku yang diganti).

- Sistem menggunakan barcode untuk mengecek informasi buku dan member untuk fungsi peminjaman dan pengembalian buku.

- Sistem dapat melakukan pencarian buku di berbagai fakultas dengan menginputkan keyword dan akan menampilkan
p-ISSN : 1858-3911, e-ISSN : 2614-5405

https://journal.uniku.ac.id/index.php/ilkom

secara otomatis fakultas perpustakaan yang memiliki buku tersebut serta stoknya.

- Yang dapat dilakukan transaksi peminjaman hanya koleksi berupa buku.

- Anggota perpustakaan hanya mahasiswa dan karyawan (termasuk dosen dan staff) di Universitas Kuningan.

Untuk hak akses dan pengguna sistem dapat dilihat pada tabel 1 .

Tabel 1. Kebutuhan Pustakawan

\begin{tabular}{|l|l|l|}
\hline No & Fungsi & Hak Akses \\
\hline 1. & $\begin{array}{l}\text { Kelola Data Master } \\
\text { (data buku, data } \\
\text { jurnal, data skripsi, } \\
\text { data koleksi lainnya) }\end{array}$ & $\begin{array}{l}\text { CRUD } \\
\text { Pelola Data }\end{array}$ \\
\hline 2. & $\begin{array}{l}\text { CRUD } \\
\text { Pelola Data }\end{array}$ & CRUD \\
\hline 3. & Laporan-Laporan & $\begin{array}{l}\text { Read dan } \\
\text { Cetak }\end{array}$ \\
\hline 4.
\end{tabular}

Tabel 2 Kebutuhan Admin Pusinfo

\begin{tabular}{|l|l|l|}
\hline No & Fungsi & Hak Akses \\
\hline 1. & $\begin{array}{l}\text { Kelola Data Master } \\
\text { (data unit kerja, data } \\
\text { program studi, data } \\
\text { admin) }\end{array}$ & CRUD \\
\hline 2. & Laporan-Laporan & $\begin{array}{l}\text { Read dan } \\
\text { Cetak }\end{array}$ \\
\hline
\end{tabular}

- Analisa Kebutuhan Non Fungsional Adapun analisa kebutuhan non fungsional dapat dilihat pada tabel 2 dan 3.

Tabel 3 Kebutuhan Pembangunan Aplikasi

\begin{tabular}{|l|ll|ll|}
\hline No & \multicolumn{2}{|c|}{ Hardware } & \multicolumn{2}{c|}{ Software } \\
\hline 1. & a. & PC Laptop & a. & Microsoft \\
& brocessor Core i3 & Windows 10 \\
& b. & RAM 3 Gb & b. & Adobe \\
& c. & HDD $120 \mathrm{~Gb}$ & & Dreamweav \\
& d. & Mouse & er CS5 \\
& e. & Printer & c. & XAMPP \\
\hline
\end{tabular}


JURNAL NUANSA INFORMATIKA

Volume 13 Nomor 1, Januari 2019

\begin{tabular}{|l|l|l|}
\hline f. & Flash disk & $\begin{array}{l}1.8 .4 \\
\text { Google } \\
\text { Chrome }\end{array}$ \\
\hline
\end{tabular}

Tabel 4 Kebutuhan Implementasi Aplikasi

\begin{tabular}{|c|c|c|c|}
\hline No & Kebutuhan & $\begin{array}{c}\text { Komputer } \\
\text { Server }\end{array}$ & $\begin{array}{c}\text { Komputer } \\
\text { Client }\end{array}$ \\
\hline 1. & Hardware & $\begin{array}{ll}\text { a. } & \text { PC Core } \\
& \text { i7 } \\
\text { b. } & \text { RAM 4 } \\
& \text { Gb } \\
\text { c. } & \text { HDD 240 } \\
& \text { Gb } \\
\text { d. } & \text { Mouse } \\
\text { e. } & \text { Keyboard } \\
\text { f. } & \text { Monitor } \\
& \text { LCD 21' } \\
\text { g. } & \text { Printer }\end{array}$ & $\begin{array}{ll}\text { a. } & \text { PC Dual } \\
& \text { Core, } 2 \\
& \text { Ghz } \\
\text { b. } & \text { RAM 2 } \\
& \text { Gb } \\
\text { c. } & \text { HDD } \\
& 120 \mathrm{~Gb} \\
\text { d. } & \text { Mouse } \\
\text { e. } & \text { Keyboar } \\
& \text { d } \\
\text { f. } & \text { Monitor } \\
& \text { LCD 14' } \\
\text { g. } & \text { Printer } \\
\text { h. } & \text { Barcode } \\
\text { Scanner }\end{array}$ \\
\hline 2. & Software & $\begin{array}{ll}\text { a. } & \text { Window } \\
\text { s 7 } \\
\text { b. } & \text { Xampp } \\
& 1.8 .4 \\
\text { c. } & \text { Google } \\
& \text { Chrome }\end{array}$ & $\begin{array}{ll}\text { a. } & \text { Window } \\
\text { s } 7 \\
\text { b. } & \text { Google } \\
& \text { Chrome }\end{array}$ \\
\hline
\end{tabular}

b. RAD Design Workshop (Workshop Desain RAD)

Adapun perancangan system dalam penelitian ini menggunakan UML, yaitu:

- Diagram Konteks

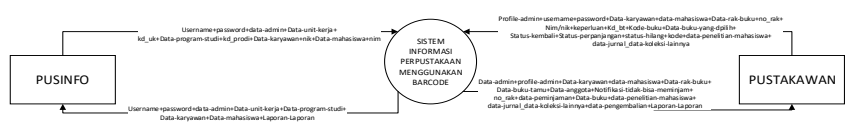

- DFD
p-ISSN : 1858-3911, e-ISSN : 2614-5405

https://journal.uniku.ac.id/index.php/ilkom

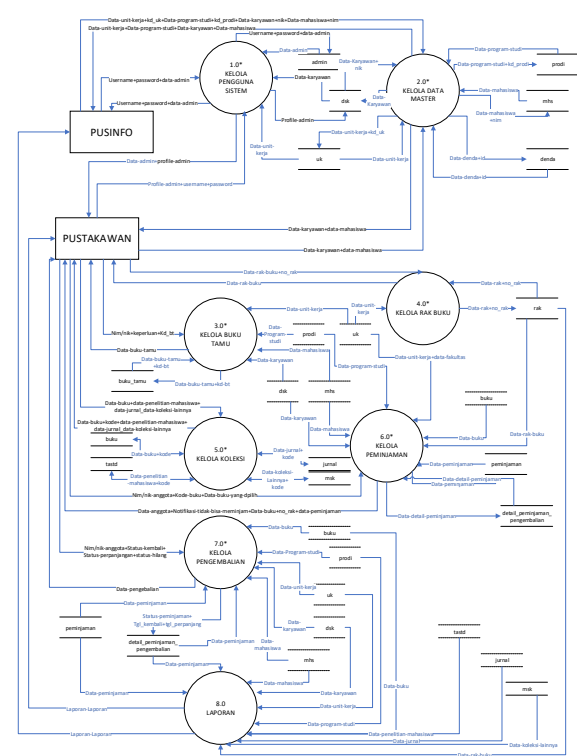

Gambar 4 DFD Level 0

- DFD Level 1 Proses 1.0 Kelola Akses User

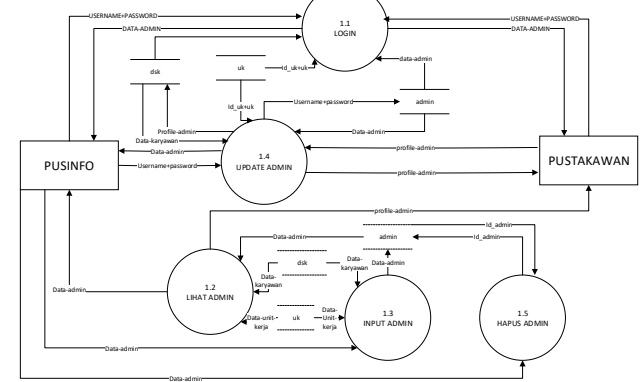

Gambar 5 DFD Level 1 Proses 1.0

- DFD Level 1 Proses 5.0 Kelola Koleksi

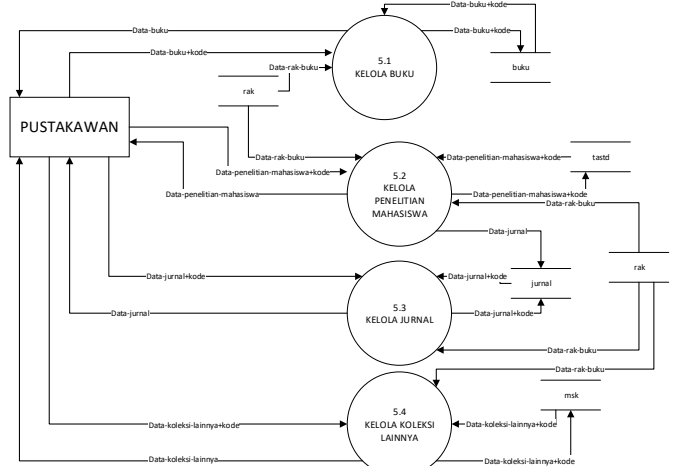

Gambar 6 DFD Level 1 Proses 5.0

- DFD Llevel 1 Proses 6.0 Kelola Peminjaman 
JURNAL NUANSA INFORMATIKA

Volume 13 Nomor 1, Januari 2019

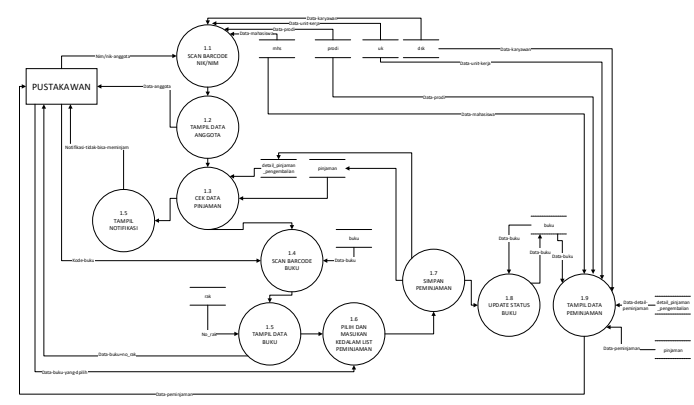

Gambar 7 DFD Level 1 Proses 6.0

- DFD Level 1 Proses 7.0 Kelola Pengembalian

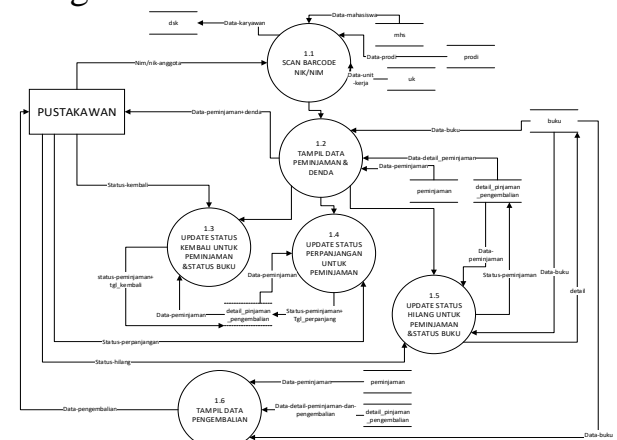

Gambar 8 DFD Level 1 Proses 7.0

- ERD

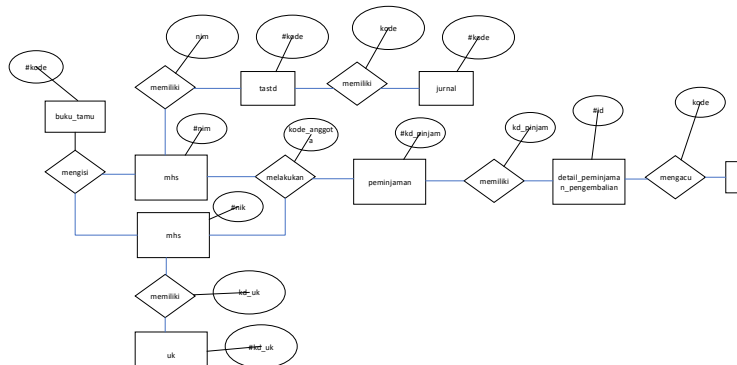

Gambar 9 ERD

*Dikarenakan Field yang terlalu banyak, maka hanya ditampilkan key-nya saja. Untuk lebih rinci dapat dilihat pada struktur tabel dibawah ini :

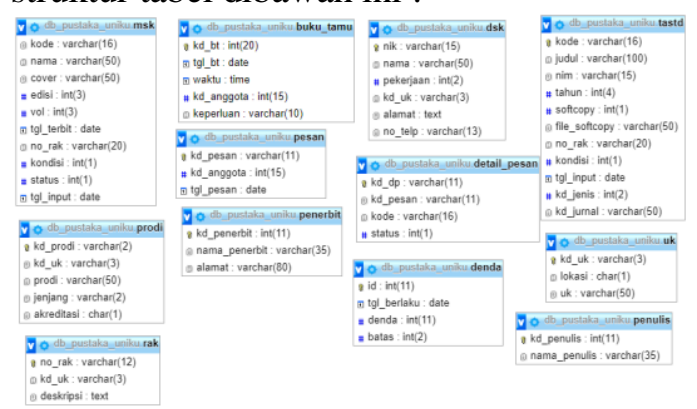

p-ISSN : 1858-3911, e-ISSN : 2614-5405

https://journal.uniku.ac.id/index.php/ilkom

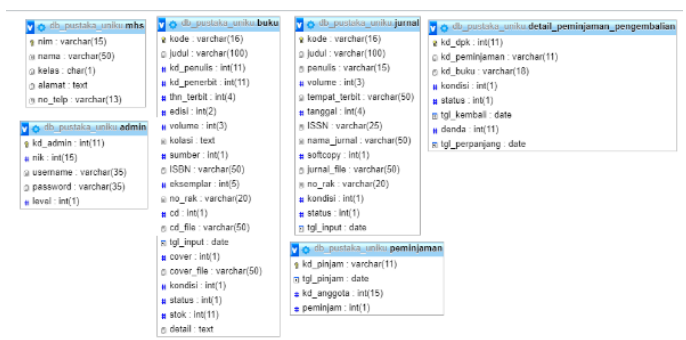

Gambar 10 Struktur Tabel

c. Implementasi

- Desain Input-Output ○ Login

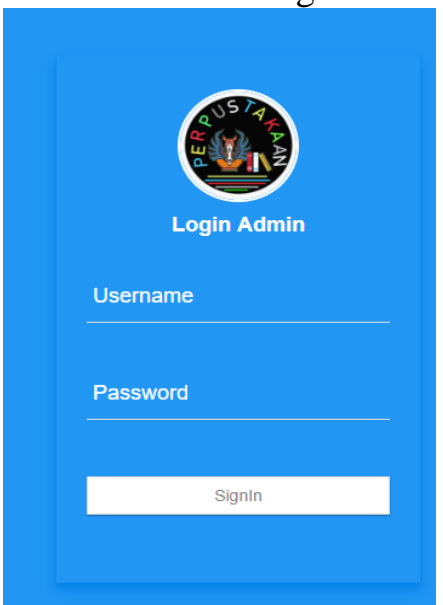

Gambar 11 Form Login

- Halaman Utama

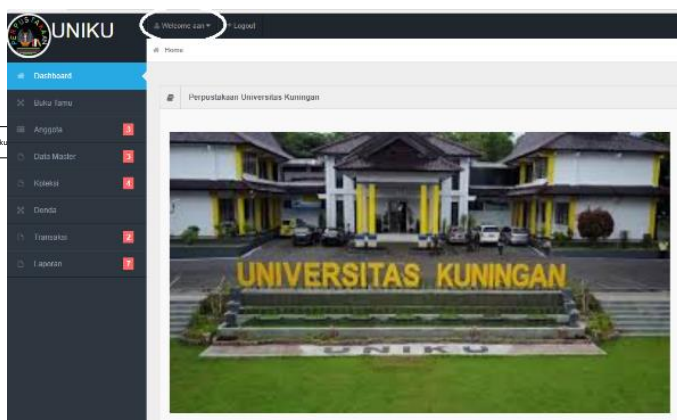

Gambar 12 Halaman Utama

Pustakawan

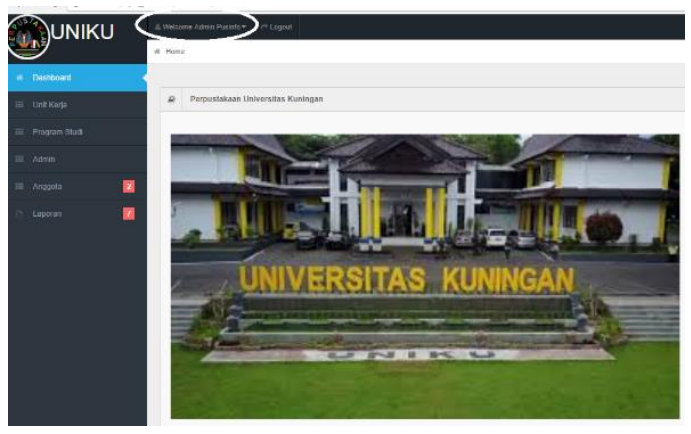

Gambar 13 Form Utama Admin Pusinfo

○ Buku Tamu 
JURNAL NUANSA INFORMATIKA

Volume 13 Nomor 1, Januari 2019

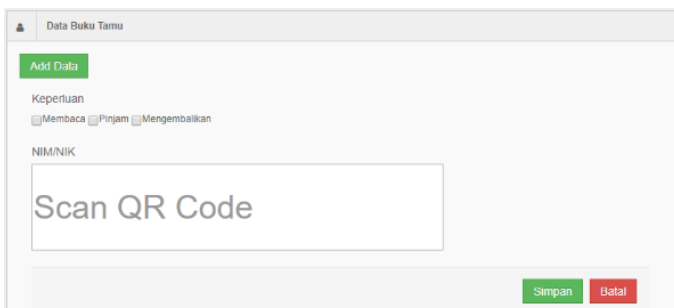

Gambar 14 Buku Tamu

\section{Scan QR Code}

$$
\text { NM }
$$$$
2015091011
$$$$
\text { Nama }
$$$$
\text { dewi }
$$$$
\text { Fakntass }
$$$$
\text { Program Studi - Jenjang }
$$$$
\text { Sistem }
$$

Gambar 15. Hasil Scan Kode Anggota pada Buku Tamu

\section{○ Buku}

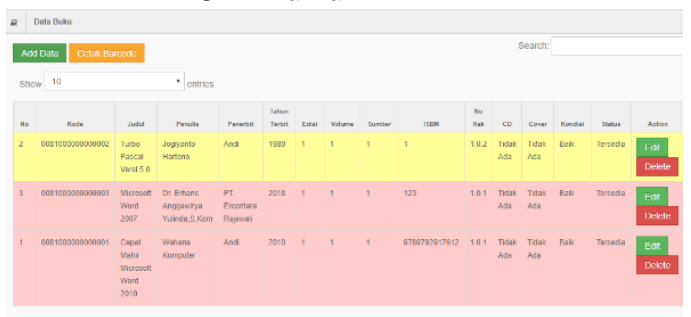

Gambar 16 Data Buku

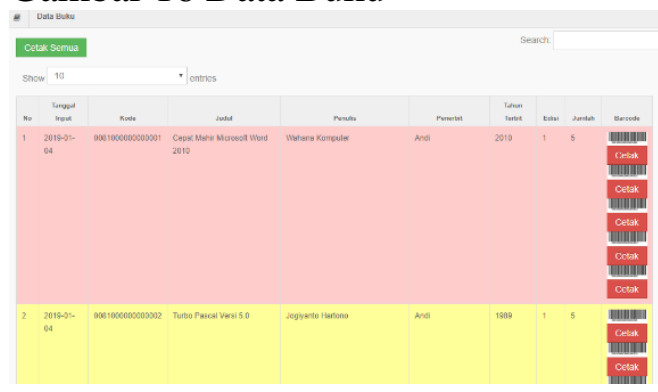

Gambar 17 Hasil Barcode Buku

○ Jurnal

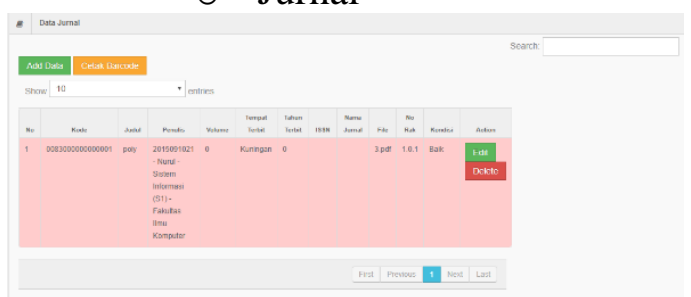

Gambar 18 Data Jurnal
p-ISSN : 1858-3911, e-ISSN : 2614-5405

https://journal.uniku.ac.id/index.php/ilkom

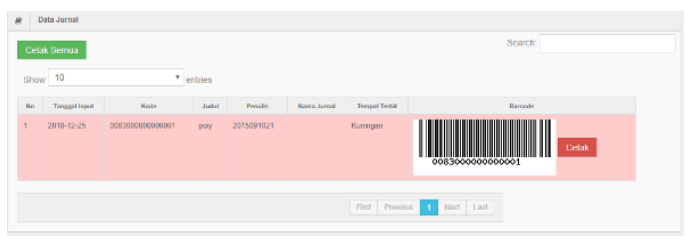

Gambar 19 Hasil Barcode Jurnal

- Laporan Hasil Penelitian Mahasiswa/Dosen

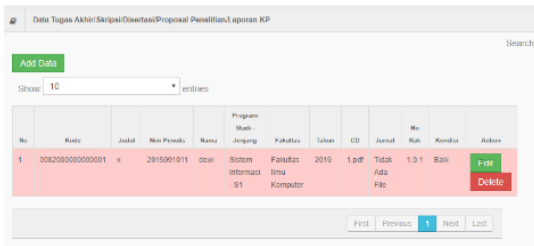

Gambar 20 Laporan Hasil Penelitian Mahasiswa/Dosen

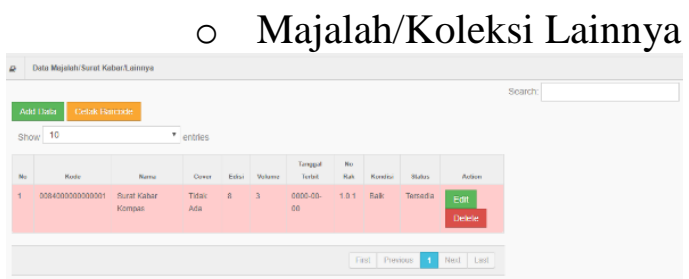

Gambar 21 Majalah/Lainnya

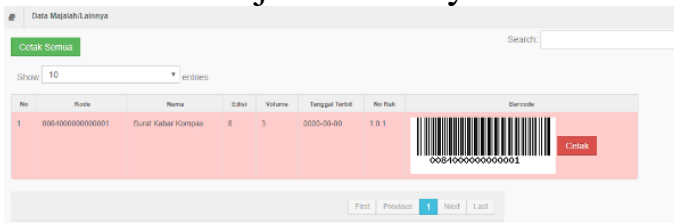

Gambar 22 Hasil Barcode Majalah/Lainnya

○ Peminjaman

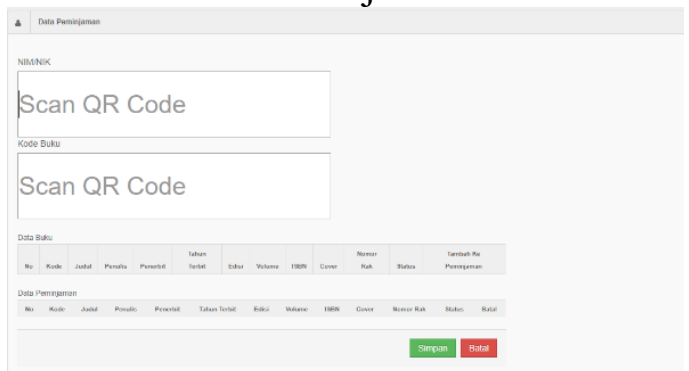

Gambar 23 Peminjaman

$\circ$ Pengembalian

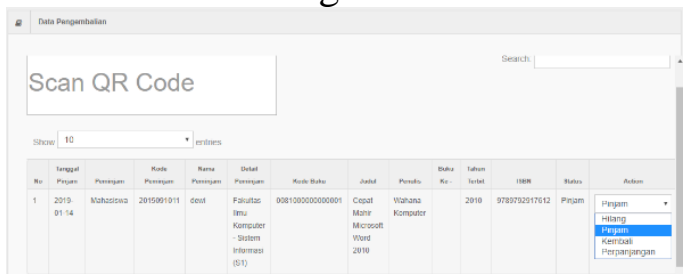

Gambar 24 Pengembalian 
JURNAL NUANSA INFORMATIKA

Volume 13 Nomor 1, Januari 2019

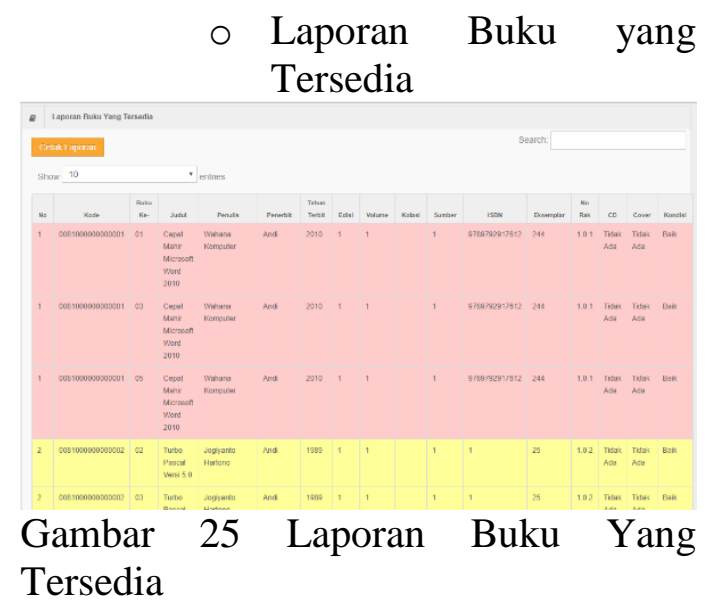
○ Laporan Buku yang Hilang

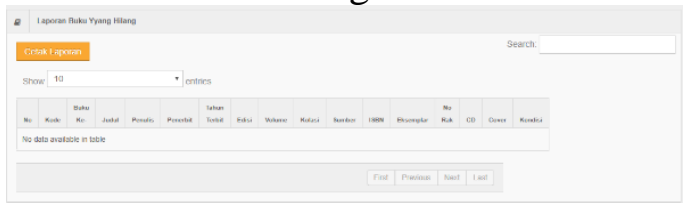

Gambar 26 Laporan Buku yang Hilang

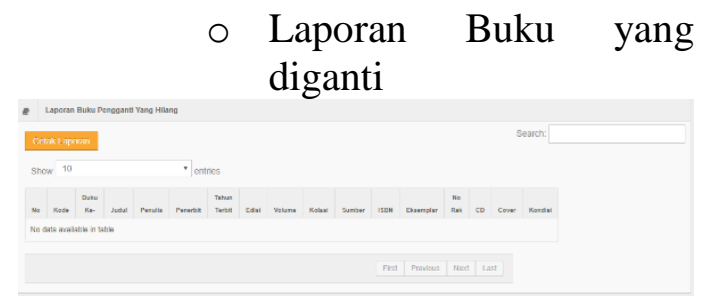

Gambar 27 Laporan Buku yng diganti

- Laporan Peminjaman

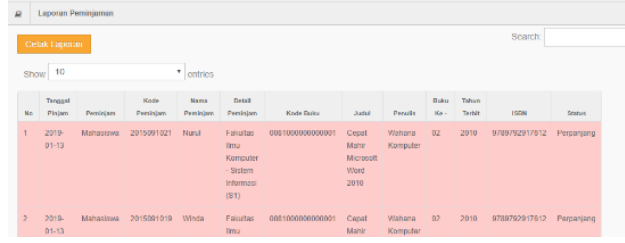

Gambar 28 Laporan Peminjaman

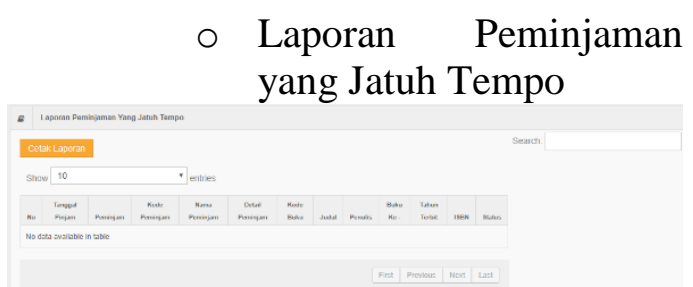

Gambar 29 Laporan Pminjaman Jatuh Tempo
p-ISSN : 1858-3911, e-ISSN : 2614-5405

https://journal.uniku.ac.id/index.php/ilkom

- Laporan Pengembalian

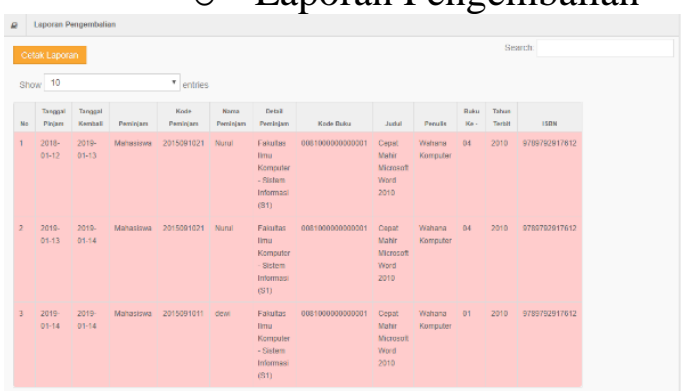

Gambar 30 Laporan Pengembalian

\section{KESIMPULAN} ini adalah:

Adapun kesimpulan dari penelitian

1. Kebutuhan pengguna dalam mengelola data anggota, data buku, kategori (buku, jurnal, skripsi, lainnya), data peminjaman, data pengembalian, denda. Sedangkan laporan yang dihasilkan berupa Laporan (Peminjaman, Laporan Peminjaman yang telah jatuh tempo, Pengembalian, Buku yang tersedia, buku yang hilang, buku yang diganti). Sistem menggunakan barcode untuk mengecek informasi buku dan member untuk fungsi peminjaman dan pengembalian buku.

2. Sistem dikembangkan menggunakan metode Rapid Aplication Development (RAD) agar tahapan pengembangannya lebih cepat sedangkan perancangannya menggunakan UML agar lebih terstruktur.

3. Hasil perancangan diterapkan kedalam bahasa pemrograman PHP dan MySQL sedangkan template web menggunakan bootstrap agar lebih optimal dalam penggunaannya.

\section{SARAN}

Agar penelitian yang dihasilkan lebih optimal, maka diharapkan :

1. Adanya pengembangan lebih lanjut mengenai pengelolaan perpustakaan 
JURNAL NUANSA INFORMATIKA

Volume 13 Nomor 1, Januari 2019

agar anggota dapat memesan data buku secara online.

2. Tools dapat dikembangkan berbasis Android agar lebih memudahkan lagi

\section{UCAPAN TERIMA KASIH}

Penulis mengucapkan terima kasih kepada LPPM Universitas Kuningan yang telah memberi dukungan financial terhadap penelitian ini.

Serta penulis mengucapakan terima kasih kepada Lembaga Universitas Kuningan khususnya Pustakawan FKOM UNIKU yang telah membantu dalam pengumpulan data penelitian.

\section{DAFTAR PUSTAKA}

[1]

https://student.cnnindonesia.com/edukasi/2 0160923142114-445-160592/mengapa-

buku-disebut-sebagai-jendela-dunia/

diakses 8 Feb 2018.

[2] Qalyubi, Syihabuddin dkk. 2003. Dasardasar ilmu perpustakaan dan Informasi. Jurusan Ilmu Perpustakaan dan Informasi Fak. Adab: Yogyakarta.

[3] UU no 43 tahun 2007 tentang Perpustakaan

[4] HM, Jogiyanto, 1999. Analisis dan Desain Sistem Informasi : Pendekatan. Terstruktur Teori dan Praktek Aplikasi Bisnis. ANDI Yogyakarta: Yogyakarta.

[5] Kendall, Kenneth E dan Kendall, Julie E. 2010. Systems Analysis And Design. Pearson Education Inc: New Jersey.

[6] M. Shalahuddin and R. A. Sukamto. 2014. Rekayasa Perangkat Lunak. (Tersruktur dan Berorientasi Objek), 2nd Edition ed.. Informatika: Bandung.
p-ISSN : 1858-3911, e-ISSN : 2614-5405

https://journal.uniku.ac.id/index.php/ilkom 